\title{
FORTALECIMENTO DA AGRICULTURA FAMILIAR COMO INSTRUMENTO PARA O DESENVOLVIMENTO RURAL DO TERRITÓRIO DE VITÓRIA DA CONQUISTA - BAHIA
}

\author{
Valdemiro Conceição Júnior \\ Ivana Paula Ferraz Santos de Brito ${ }^{2}$
}

\section{RESUMO}

Este artigo traça um panorama das atividades de extensão realizadas entre os anos de 2000 a 2010, que tiveram como objetivo o desenvolvimento rural do Território de Vitória da Conquista (TVC). Com a realização do primeiro Seminário sobre Perspectivas para o Desenvolvimento Rural, aconteceram diversos debates e ações efetivas, os quais focaram: a geração de mais oportunidades de trabalho e renda no campo, a segurança alimentar, o estímulo ao empreendedorismo dos agricultores familiares, a conservação e o uso racional dos agroecossistemas. Essas ações possibilitaram a articulação de diversas organizações, entidades e movimentos sociais, o fortalecimento da organização rural e a capacitação de produtores, profissionais, jovens e estudantes nas diversas temáticas que envolvem a agricultura familiar, como também o crescimento rural. Como resultados mais concretos podem ser citados a criação do Colegiado do Território, a formação do Conselho Quilombola e a organização de seis cooperativas que integram a Rede de Cooperativas da Agricultura Familiar do TVC.

Palavras-chave: Agricultura Familiar. Desenvolvimento Rural. Extensão Rural.

\footnotetext{
${ }^{1}$ Professor Doutor Pleno do Departamento de Fitotecnia e Zootecnia da Universidade Estadual do Sudoeste da Bahia (UESB). Coordenador do Grupo de Pesquisa em Desenvolvimento Rural Sustentável. E-mail: miroconceicao@hotmail.com

${ }^{2}$ Mestre em Agronomia (Fitotecnia) pela UESB. E-mail: ivanapaulaf@yahoo.com.br

\begin{tabular}{l|l|l|l|l}
\hline Revista Extensão \& Cidadania & Vitória da Conquista & v. 1, n. 1 & p. 121-141 & jan./jun. 2013 \\
\hline
\end{tabular}
}




\title{
Familiar agriculture strengthening as instrument for the territory of Vitoria da Conquista - Bahia rural development
}

\begin{abstract}
This article traces an extension activities panorama carried through between the years of 2000 and 2010 aimed the Territory of Vitória da Conquista (TVC) rural development. From the beginning, when the first Seminar on Perspectives for Rural Development occurred, many effective discussions and actions aimed to generate more job opportunities and income in rural areas, food security, familiar agriculturists entrepreneurship encouragement, conservation and rational use of agroecosystems were developed. These actions enabled to articulate various organizations, entities, and social movements, and producers, professionals, young people and students training on various subjects involving small holders and rural development. As more concrete results can be cited the Territory's Collegiate creation, the Quilombola's Council formation, and six cooperatives organization that make up the TVC Familiar Agriculture's Cooperatives Net.
\end{abstract}

Keywords: Small Holders. Rural Development. Rural Extension.

\section{Programa de Desenvolvimento Rural Sustentável}

A agricultura é uma importante fonte de renda no Estado da Bahia e, no que diz respeito aos agricultores familiares, são mais de 600.000 famílias, o maior contingente por estado do país. Segundo informações de Brasil (2000), dos 24 municípios que compõem o Território de Vitória da Conquista (TVC), 16 possuem mais de 95\% dos estabelecimentos rurais classificados como familiares, tendo, de acordo com o Estudo das Potencialidades Econômicas (EPE/TRVC, 2007), um total de 34.444 propriedades em pouco mais de 1.000 .000 ha. Dentre essas propriedades estão também assentados de reforma agrária e remanescentes de quilombos, geralmente com o mínimo de relações com o mercado formal, muitos sobrevivendo em situação de pobreza extrema.

Sendo assim, a agricultura familiar exerce papel fundamental na região e, dessa forma, a discussão sobre sua importância e protagonismo no desenvolvimento regional tem ganhado força 
nos últimos anos, impulsionando debates e ações efetivas. Tais atividades têm gerado mais oportunidades de trabalho e renda no campo, a segurança alimentar, o estímulo ao empreendedorismo dos agricultores familiares, a conservação e o uso racional dos agroecossistemas.

Durante muito tempo, os programas de desenvolvimento se fundamentavam apenas nos aspectos econômicos, com o agravante de serem geralmente concebidos por técnicos lotados em instituições distantes das condições culturais, educacionais e ambientais do município em questão, quase sempre desconsiderando as peculiaridades locais, bem como os anseios da comunidade. Esses programas, assim como as políticas assistencialistas e/ou compensatórias, que foram implementadas para minorar o desequilíbrio social do país, tiveram resultados quase insignificantes em promover a melhoria da qualidade de vida.

Desenvolver o campo significa colocar em prática ações estruturantes que viabilizem seu fortalecimento, e deve ser um investimento em toda a população, evitando o empobrecimento de parte importante desta, o qual tem como consequências iniciais o êxodo, o desemprego, a exclusão social e a geração de diversos problemas urbanos.

Segundo Brasil (2001), essas ações integram a extensão, parte de um processo que tem por objetivo maior melhorar a qualidade de vida dos grupos sociais, e, nesse sentido, éde fundamentalimportância que ações a serem trabalhadas nos grupos sejam demandas reais; caso contrário, a probabilidade de retorno à condição inicial após o final do trabalho de extensão será grande.

Dessa forma, este artigo traça um panorama das atividades de extensão realizadas entre os anos de 2000 a 2010, cuja execução tem por fim o desenvolvimento rural do Território de Vitória da Conquista. 


\section{Caracterização Local}

O município de Vitória da Conquista, segundo maior do interior do Estado da Bahia, tem a agricultura familiar como modalidade predominante em seus estabelecimentos rurais e é a responsável por grande parte do abastecimento alimentar e da ocupação da população local que trabalha na agricultura (ABREU; BRITO; CONCEIÇÃO JUNIOR, 2008). A atividade agrícola regional desperta atenção em razão do potencial de sustentabilidade para a agricultura familiar, por ser de tradição histórica e um importante fator de geração de trabalho e renda. Entretanto, para Pereira et al. (2006), o conhecimento restrito dos sistemas de produções adotados limitava a implementação de programas e ações adequadas.

Com o intuito de minimizar esse entrave, foram executados, entre os anos de 2005 e 2009, os projetos de pesquisa "Análise dos sistemas rural-urbanos do município de Vitória da Conquista - BA" e "Análise dos sistemas agrários do território de Vitória da Conquista - BA: Um diagnóstico do meio rural e suas perspectivas de desenvolvimento", com o apoio da UESB, e permitiram conhecer profundamente a dinâmica da agricultura realizada na região, em especial para o segmento familiar.

Para isso, utilizaram-se aspectos do Guia Metodológico Análise Diagnóstico de Sistemas Agrários (GARCIA FILHO, 1999), e como metodologia, inicialmente, foi feito o levantamento de informações secundárias e entrevistas com profissionais e lideranças locais, e, posteriormente, a realização de visitas de campo em três fases distintas: leitura de paisagem, entrevistas com moradores mais antigos das localidades e aplicação de questionários pré-estruturados nos diferentes anos, totalizando mais de 700 questionários.

Em virtude da grande diversidade da agricultura familiar, é comum a falta de uniformidade dos critérios classificatórios (EPE/TRVC, 2007). O modelo familiar pode ser classificado, segundo Cremonese e Schallenberger (2005), pela caracterização da direção do processo 
produtivo, da força de trabalho, da gestão da propriedade pelo núcleo familiar e do patrimônio; os ativos podem ser objeto de herança entre as gerações (GASSON; ERRINGTON, 1993) e, de acordo com o Programa Nacional de Fortalecimento da Agricultura Familiar, pela área disponível, pela renda e origem desta.

Diante dessas condicionalidades, as informações levantadas nas entrevistas e nas etapas de campo permitiram inferir que o modo principal de agricultura desenvolvido na região pode ser classificado como tal. Os dados obtidos evidenciaram que a administração das unidades rurais é realizada, em sua maioria, pelos proprietários e família, e o tipo de mão de obra comumente empregada era a familiar. A terra, na maior parte das unidades, trata-se de uma herança familiar, em que são herdados não só o espaço físico, mas também conceitos e costumes utilizados na manutenção da integridade do patrimônio (MENEZES et al., 2007).

Segundo Otani et al. (2000), esse setor da agricultura deve ser rigorosamente entendido como um segmento que detém poder de influência econômica e social. Os dados relativos à economia dos produtores devem, sobretudo, estimular uma reflexão mais aprofundada sobre a capacidade de acumulação e sobre as tendências de evolução de cada categoria de produtores e dos sistemas de produção (ARAÚJO JÚNIOR, 2003).

Mesmo utilizando a mão de obra disponível, a contratação parcial ocorre, ainda que em pequena quantidade, em épocas determinadas do ano, quando há maior quantidade e intensidade de trabalho, como o plantio e a colheita. O pagamento é geralmente realizado pelo sistema de diárias, sem registro em carteira de trabalho e vínculo do contratante com o trabalhador (FARIAS et al., 2007).

Nas propriedades cultivam-se diversas culturas, fator que também contribui para a maior eficiência na utilização da mão-de-obra familiar. Nesses sistemas, a colheita ocorre em separado, viabilizando os tratos a serem realizados e a comercialização em diferentes épocas, o que, por sua vez, ocasiona uma receita bem distribuída durante todo 
o ano, diminui os riscos climáticos (CONCEIÇÃO JUNIOR et al., 2008) e de interferências de pragas e doenças (ALTIERI; NICHOLS, 1999) e a renda familiar não fica sujeita ao mercado de um único produto (ABREU; BRITO; CONCEIÇÃO JUNIOR, 2008). Essa diversidade permite uma alimentação bastante variada e refletese também em maior qualidade nutricional para a família, levando em conta que o autoconsumo foi considerado o principal destino da produção agrícola na região e os produtores podem, se houver excedentes, até conseguir uma renda extra (MENEZES et al., 2007).

As áreas em sua maioria são limitadas e, mesmo assim, notou-se que é possível sobreviver e gerar renda para o sustento da família, considerando as possibilidades agrícolas e não agrícolas de uma propriedade. A diversidade de culturas permite também um melhor aproveitamento de tais áreas, e, consequentemente, maior geração de renda agrícola, ou alimentos para a família no mesmo espaço.

A renda média oriunda dos estabelecimentos agrícolas girava em torno do salário mínimo vigente no ano de 2006, e, com o passar do tempo, as análises realizadas em 2009 permitiram verificar o aumento da renda das famílias. A renda auferida pelos agricultores, além das agrícolas, é proveniente de atividades exógenas no comércio, em fábricas e casas de famílias, estas principalmente na sede do município de Vitória da Conquista, e da venda de diárias para propriedades próximas. Além dessas atividades, Farias et al. (2007), destacaram-se também outras fontes de renda como aposentadorias e programas sociais.

A aposentadoria rural, segundo Deus et al. (2010), tem extrema importância no orçamento e proporciona mais segurança para a família rural. Ao terem garantido os recursos para atender as despesas básicas da família, principalmente a alimentação, os seus membros podem se dedicar mais ao cultivo de sua propriedade, o que faz aumentar a renda da agricultura e diminuir a dependência da venda de diárias.

Papel semelhante tem sido desempenhado pelo Bolsa Família, principal programa social para as famílias do campo, o qual, diferente do que tem sido propalado pelo senso comum, não é responsável 
pelo abandono de postos de trabalho, nem pela redução da produção agrícola, segundo Vieira et al. (2010), funcionando antes como um instrumento de incentivo que favorece a distribuição de renda e gera alternativas de trabalho para a população rural, tornando-a mais capaz de buscar sua autonomia.

No que se refere à assistência técnica para a condução da produção e da propriedade, $76 \%$ dos empreendimentos do território não têm acesso a este serviço (BRITO et al., 2009). Essa realidade tem duas vertentes distintas: os que contam com o acompanhamento tendem a seguir o modelo tradicional de produção e aliam altos custos de pacotes tecnológicos com pouca ou nenhuma proteção dos recursos naturais. Por outro lado, a falta de acompanhamento adequado implica o não aproveitamento do potencial da propriedade, a utilização inadequada das tecnologias aprendidas com outras gerações, e, consequentemente, a menor geração de renda. Como pode ser visto, as duas situações são insustentáveis e indicam que a adoção de uma assistência técnica que respeite os saberes tradicionais e que maximize a utilização dos recursos locais pode permitir a essas comunidades o desenvolvimento de sistemas de produção mais sustentáveis (BRITO et al., 2009).

Aliado a certas restrições para a produção, a dificuldade de comercialização reduz a rentabilidade das propriedades. O grande problema não é escoar a produção, diante da possibilidade e grande atuação de intermediários no processo produtivo da região em estudo, mas sim comercializar direto para o consumidor, o que possibilitaria maiores lucros para o produtor. De acordo com Menezes et al. (2007), a maioria dos agricultores do TVC destina a produção a atravessadores.

\section{Ações extensionistas}

As ações extensionistas, que objetivam o desenvolvimento do TVC, tiveram início no ano 2000, com a realização do Seminário sobre Perspectivas para o Desenvolvimento Rural, no Teatro Glauber 
Rocha, na Universidade Estadual do Sudoeste da Bahia (UESB), com a participação de mais de 400 agricultores. O seminário serviu como base para a criação do Programa Municipal de Desenvolvimento Rural de Vitória da Conquista, financiado inicialmente pela Pró-Reitoria de Extensão da UESB.

Por se tratar de um município extenso e com características bastante diferenciadas, verificou-se a necessidade de fazer recortes, dividindo-o em 5 regiões principais, o que permitiu, dentre outros fatores, a realização de trabalhos de estímulo à organização dos produtores e fortalecimento das associações locais já existentes. Por consequência natural, foram impostas novas demandas, pela necessidade da implementação de ações estruturantes, sendo assim constituídos os Conselhos de Desenvolvimento Rural Sustentável em cada região, os quais foram formados por representantes de todas as comunidades presentes naquela área.

Esses conselhos tinham como principal objetivo elaborar o Plano de Desenvolvimento Rural Sustentável de sua região e, a partir deste, articular a implementação dos projetos prioritários com os órgãos das esferas municipal, estadual e federal, como também acompanhar a execução dos projetos alcançados. Para tal, aprovou-se na UESB um projeto de capacitação para os membros dos conselhos, com a participação de diversos professores dos cursos de Agronomia, Geografia, História, Letras, Administração, entre outros. A partir da capacitação, eles passaram a se reunir mensalmente com o apoio de um técnico para dar suporte às ações, geralmente um engenheiro agrônomo da Prefeitura Municipal de Vitória da Conquista (PMVC).

Vitória da Conquista é o município polo da região onde está inserido e tem sua economia centrada no comércio, no setor de serviços, na indústria e, em menor escala, na agropecuária, enquanto os demais municípios da região têm a economia baseada quase que exclusivamente na agricultura, principalmente, na agricultura familiar. Por meio dela, os agricultores comercializam e sobrevivem de cultivos de subsistência e pequenas criações. Com essa realidade e 
a necessidade de buscar algo mais concreto para o desenvolvimento regional, notou-se que as ações isoladas no primeiro município não seriam suficientes, e desse modo, iniciou-se a expansão do projeto para municípios mais próximos.

Com o apoio do Ministério de Desenvolvimento Agrário (MDA) e da PMVC, por meio da Secretaria de Expansão Econômica, foi executado o projeto de Capacitação, Assistência Técnica e Extensão Rural, nos anos de 2003 e 2004, que possibilitou a agricultores da microrregião de Vitória da Conquista, Cândido Sales e Barra do Choça o conhecimento de novas possibilidades produtivas, acompanhamento técnico especializado e capacitações nas diferentes áreas relacionadas ao seu campo de trabalho.

Dessa forma, foram realizadas nesse período, a I e a II Semana da Agricultura Familiar, com o objetivo de desencadear um amplo debate, em busca de alternativas sociais, econômicas, ambientais e culturais para a agricultura familiar de Vitória da Conquista e região. O evento aconteceu por meio da promoção de palestras, debates e exposição de temas e produtos que valorizaram e divulgaram as iniciativas locais e regionais. Esses eventos foram uma forma de apresentar aos agricultores, familiares tradicionais, assentados, estudantes, profissionais da área de ciências agrárias, professores, pesquisadores e entidades que desenvolvem ações voltadas para agricultura familiar na região, as proposições para o desenvolvimento rural e as experiências bem sucedidas, demonstrando a possibilidade real de alcançar resultados.

As semanas se constituíam ainda no espaço próprio para avaliar as atividades desenvolvidas pelos diversos movimentos e parceiros, como a Articulação no Semi-Árido (ASA); o Centro de Convivência e Desenvolvimento Agroecológico do Sudoeste da Bahia (CEDASB); o Movimento de Trabalhadores Desempregados (MTD), o Movimento dos Pequenos Agricultores (MPA), o Movimento dos Trabalhadores Sem Terra (MST); o Pólo Sindical; o Sindicato de Trabalhadores Rurais da Região de Vitória da Conquista (STR-VC); a Universidade 
Estadual do Sudoeste da Bahia (UESB); a Prefeitura Municipal de Vitória da Conquista (PMVC); o Instituto Mata de Cipó; o Ministério da Agricultura Pecuária e Abastecimento (MAPA); o Sistema Brasileiro de Apoio às Micro e Pequenas Empresas (SEBRAE); a Empresa Baiana de Desenvolvimento Agrícola (EBDA) e o Instituto Nacional de Colonização e Reforma Agrária (INCRA).

Apesar da necessidade do debate, Cavaco (1996) afirmou que para o processo de desenvolvimento ter sucesso é necessária certa homogeneidade em relação aos grupos envolvidos, com expectativas, motivações e cultura em sintonia, e com o comprometimento necessário, visto ser um processo de longo prazo, que pode causar frustração em alguns momentos.

Pelos bons resultados alcançados e com cada vez mais segmentos da sociedade dispostos a se envolverem no processo, a PMVC, no final do ano de 2004, criou a Secretaria de Agricultura e Desenvolvimento Rural. Tal iniciativa possibilitou a consolidação das ações desenvolvidas até então e a ampliação das atividades a serem realizadas posteriormente. Um fator importante nesse processo foi o entendimento daquela gestão municipal de que o desenvolvimento sustentável de Vitória da Conquista passava pelo fortalecimento dos municípios vizinhos, o que a levou a apoiar a estruturação da agricultura familiar no Território.

No ano de 2005, então, foi realizada a III Semana da Agricultura Familiar. O evento teve como objetivo fomentar o debate de forma a contribuir para o desenvolvimento rural sustentável, geração de trabalho, renda e inclusão social da agricultura familiar, por meio do incentivo ao protagonismo dos atores sociais e da adoção de processos produtivos de base ecológica. Houve a participação de 460 agricultores e lideranças dos 27 municípios, com palestras, debates, minicursos, e, pela primeira vez, a formação de Grupos de Trabalho (GTs). Nestes grupos, formados sobre temas específicos, como assentamentos e organização da produção familiar, colocou-se em discussão a questão do reconhecimento das comunidades quilombolas e a política 
de divisão do país em Territórios de Identidade, questões até então desconhecidas por grande parte do público. Como resultados desses GTs, foram delineadas estratégias de ação, principalmente para a questão dos quilombolas e da consolidação do Território.

Um dos fatores considerados para a identificação e posterior reconhecimento de uma comunidade como quilombola é a presença de herança territorial e cultural. No Território, a maioria das propriedades foi herdada de antepassados, o que se confirma pela presença dos ancestrais nas regiões (BRITO et al., 2009). Esse modo de aquisição das terras figura como fator para explicação das reduzidas áreas encontradas nas comunidades quilombolas, pois as famílias numerosas dividem e redividem as propriedades (EPE/TRVC (2007), e, muitas vezes, têm irregularidades no título de posse, comumente por serem mantidos os nomes de antecessores. O problema dificulta, dentre outras coisas, o acesso a financiamentos agrícolas vigentes. Nessa herança cultural estão presentes também práticas de uso e manejo dos recursos naturais (SANTOS et al., 2009), nem sempre muito adequadas para a preservação do meio ambiente.

Na região, a característica principal dos grupos está relacionada à sua origem. A maioria deles, segundo a PMVC (2009), não surgiu durante o período da escravidão, mas após a abolição, quando a terra se tornou moradia e fonte de alimento por meio da agricultura de subsistência, ou seja, era a principal garantia de sobrevivência de pessoas que não conseguiam trabalho formal.

Com o decorrer do projeto, verificou-se a relevante presença de comunidades remanescentes de quilombos na região, definidas como Grupos étnico-raciais, segundo critérios de autodefinição, com trajetória histórica própria, dotados de relações territoriais específicas com presunção de ancestralidade negra relacionada com a resistência à opressão histórica sofrida (BRASIL, 2008). Em 2009, o estado da Bahia possuía, segundo dados do MDS (BRASIL, 2009), 292 comunidades quilombolas certificadas, o que significa quase 25 mil famílias. No (TVC), mais de 60 comunidades já foram identificadas 
como remanescentes de quilombos, e apenas no município de Vitória da Conquista existiam 23 comunidades já reconhecidas pela Fundação Cultural Palmares (BRITO et al., 2009).

Também como reflexo das discussões iniciadas na III Semana da Agricultura Familiar, as ações deixaram de ser microrregionais e passaram a ser territoriais, segundo o então novo modelo de regionalização, criado pelo Ministério de Desenvolvimento Agrário (MDA), por meio da Secretaria de Desenvolvimento Territorial e do Programa Nacional de Desenvolvimento Sustentável (PRONAT). Este modelo dividiu todo o país em Territórios de Identidade a partir do ano de 2003, a fim de subsidiar a execução e acompanhamento de ações destinadas à agricultura familiar e aos movimentos de luta pela terra no país (EPE/TRVC, 2007).

Inicialmente, a Bahia foi dividida em 22 territórios, totalizando desde 2005 o número de 26, sendo o Território da Região de Vitória da Conquista (TRVC) composto por 24 municípios (Vitória da Conquista, Anagé, Aracatu, Barra do Choça, Belo Campo, Bom Jesus da Serra, Caetanos, Cândido Sales, Caraíbas, Condeúba, Cordeiros, Encruzilhada, Guajeru, Jacaraci, Licínio de Almeida, Maetinga, Mirante, Mortugaba, Piripá, Planalto, Poções, Presidente Jânio Quadros, Ribeirão do Largo, Tremedal), que compreende uma área que vai do Planalto de Conquista à parte oeste da Serra Geral (CONCEIÇÃO JUNIOR; SANTOS, 2008). Após solicitação da Coordenação Estadual dos Territórios de Identidade da Bahia (CET), a sigla passou a ser TVC.

Com a criação do colegiado do TVC e estruturação de um fórum territorial com oito representantes de cada município, houve uma participação mais ativa dos beneficiários em todas as discussões, articulação e elaboração de projetos compensatórios e estruturantes para suas comunidades.

Com essa possibilidade de atuar em diversos municípios foi possível realizar trabalhos de organização social, assistência técnica e consultorias com o apoio do MDA também em Planalto, Poções, Nova Canaã e Barra do Choça. Nos demais municípios o apoio dado teve 
ênfase nos trabalhos de fomento, na organização rural e na articulação para o acesso às políticas públicas de fortalecimento da agricultura familiar, segurança alimentar e comercialização, e para a formação de cooperativas familiares na região.

Um fato que parece ser importante e estar relacionado ao aumento da renda é a organização de agricultores familiares em associações ou cooperativas, fator importante para a viabilização e competitividade dos produtores no mercado. Nesse sentido, foi de grande valia a atuação do Projeto de Desenvolvimento Comunitário da Região do Rio Gavião (Pró-Gavião), realizado entre 1997 e 2006, executado pela Companhia de Desenvolvimento e Ação Regional (CAR), com financiamento do Fundo Internacional de Desenvolvimento Agrícola e apoio da Embrapa Semi-Árido e Embrapa Mandioca e Fruticultura, atendendo 13 municípios da bacia do Rio Gavião: Anagé, Belo Campo, Caraíbas, Condeúba, Cordeiros, Guajeru, Jacaraci, Licínio de Almeida, Maetinga, Mortugaba, Piripá, Presidente Jânio Quadros e Tremedal, todos pertencentes ao TVC.

A participação de membros da UESB na segunda fase do PróGavião tinha o objetivo de apoiar a comercialização e a definição da proposta de organização rural que originou a formação de quatro cooperativas na região em 2005. As cooperativas giram em torno das cadeias produtivas da cana-de-açúcar, do leite, da mandioca e do mel, assim como a proposição de um modelo coletivo de negócios sob forma de central. Em um segundo momento foi realizado o seminário de prospecção de demandas de projetos para a modernização e adequação dos microempreendimentos rurais, agroindústrias de base familiar e fortalecimento das cooperativas.

A Cooperativa dos Produtores dos Derivados de Leite da Região do Rio Gavião (COODELEITE), a Cooperativa dos Produtores dos Derivados de Cana-de-açúcar da Região do Rio Gavião (COODECANA), a Cooperativa dos Produtores de Mel da Região do Rio Gavião (COOPMEL) e a Cooperativa dos Produtores dos Derivados de Mandioca da Região do Rio Gavião (COOPERMAN) 
são formadas por mais de 600 cooperados e agricultores familiares, e juntas formam, desde então, a Central de Cooperativas da Região do Vale do Rio Gavião, que é responsável pela comercialização dos produtos e oferece todo suporte técnico necessário.

Também em 2005, com o apoio da Fundação Banco do Brasil, segundo premissas do Programa Fome Zero, surgiu a Cooperativa Mista de Pequenos Agricultores do Sudoeste da Bahia (COOPASUB) formada por cooperados, agricultores familiares de dezoito municípios do Sudoeste da Bahia, Anagé, Aracatu, Barra do Choça, Belo Campo, Boa Nova, Bom Jesus da Serra, Cândido Sales, Caraíbas, Condeúba, Encruzilhada, Mirante, Nova Canaã, Planalto, Piripá, Poções, Ribeirão do Largo, Tremedal e Vitória da Conquista, que têm como principal atividade o cultivo de mandioca. Atualmente, com mais de 2000 cooperados, a COOPASUB tem articulação com os diferentes movimentos sociais agrários e por meio do seu complexo industrial, com capacidade de processar 100 ton/dia, está industrializando as raízes para transformar em fécula, além de padronizar, embalar e comercializar farinha, agregando valor e aumentando a lucratividade dos cooperados, que produzirão a maioria da mandioca utilizada.

Já a Cooperativa de Pequenos Agricultores de Café de Barra do Choça (COOPERBAC) foi criada com o objetivo de fomentar a organização dos agricultores familiares do município para melhorar a qualidade e a comercialização dos seus produtos e dar uma melhor qualidade de vida ao produtor rural.

Com organizações como essas, se tornou possível a aquisição de insumos e contratação de assistência técnica com preços menores, o que está diretamente ligado à possibilidade da comercialização de produtos in natura em maior quantidade e melhor qualidade, e, principalmente, a viabilização da agregação de valor pela agroindustrialização. Realizouse então, no ano de 2006, a IV Semana da Agricultura Familiar com ênfase na estruturação das cadeias produtivas.

É possível notar na região que a cultura associativista e cooperativista tem se fortalecido, superando as experiências 
malsucedidas, a fim de melhorar o processo produtivo, inclusive alcançar mercados mais compensadores e consequentemente mais exigentes, como o Comércio Justo. Esse modo de comercialização que estabelece um preço mínimo que cobre os custos de produção e garante uma margem de lucro para o produtor, foi apresentado pela primeira vez na região durante o I Encontro de Comercialização de Produtos da Agricultura Familiar. O evento contou com a participação de produtores de todo o TVC.

Com o propósito de ampliar as opções de comercialização pelos agricultores, foram desenvolvidas várias ações, inicialmente, nos municípios de Vitória da Conquista, Cândido Sales, Barra do Choça, Poções, Planalto e Nova Canaã, para possibilitar o ingresso dos produtores no Programa de Aquisição de Alimentos (PAA), Compra Direta, que se dá em parceria com a Companhia Nacional de Abastecimento (CONAB). O programa, que desde 2006 passou a ter recursos orçamentários próprios destinados pelo MDA para sua operacionalização, tem como objetivos garantir o acesso a alimentos às populações em situação de insegurança alimentar e nutricional, e permitir aos agricultores familiares que armazenem seus produtos para que sejam comercializados a preços mais justos.

Com a atuação da COOPASUB, cooperados dos municípios do Planalto de Conquista e entorno tiveram seus produtos vendidos e repassados às escolas, pastorais e instituições de caridade. Na região do Vale do Rio Gavião e Serra Geral a COOPERMAN, COODELEITE, COOPERCANA e COOPMEL têm cumprido esse papel junto aos seus cooperados. Em Barra do Choça esse processo é realizado pela COOPERBAC. Ressalta-se que as cooperativas têm envidado esforços para comercializar todos os produtos de seus cooperados e não apenas aqueles que são objeto principal de sua atuação, no caso, mandioca, leite, cana-de-açúcar, mel e café, seguindo a ordem acima de citação das cooperativas.

Com essa maior organização e inserção do Território nas atividades voltadas ao desenvolvimento rural, foram realizadas em 
2007 e 2008 a V e VI Semana da Agricultura Familiar, respectivamente, e em paralelo a I e II Semana da Agricultura Familiar do Território de Vitória da Conquista. As conferências promoveram debates sobre uso de tecnologias alternativas e ecológicas, socialmente apropriadas para a produção agropecuária, disponibilizaram ao público informações sobre as políticas públicas voltadas para a agricultura familiar e elaboraram uma agenda de trabalho com os parceiros da sociedade civil organizada.

\section{Considerações Finais}

Os benefícios gerados pelos projetos executados são visíveis, tanto para o produtor e sua família, quanto para a região em questão. Entretanto, notam-se ainda grandes necessidades por parte dos agricultores familiares da região, que poderão ser ao menos em parte reduzidas, visto as possibilidades reais da continuação de atividades como essas.

Ao realizar projetos que estimulam e trabalham pelo desenvolvimento e melhoria da qualidade de vida da população, é necessário que haja na região profissionais capacitados a suprir as diferentes demandas que a partir desse momento se apresentam. Desta forma, com o intuito de melhorar a formação discente, além da participação efetiva destes como bolsistas de extensão, estagiários, monitores ou voluntários, foram realizados diversos eventos na universidade, buscando envolver o alunado em geral.

Dentre eles, podem ser destacados a I Semana de Engenharia Florestal do Sudoeste da Bahia e a V Semana de Agronomia da UESB, que possibilitaram em 2009 e 2010 a aproximação dos estudantes e da universidade com a realidade dos produtores da região. Os discentes também adquiriram novos conhecimentos, a troca de experiências entre pesquisadores pelas apresentações dos projetos de pesquisa e extensão desenvolvidos e a formação extracurricular com os minicursos ministrados. Esses eventos continuam a ser realizados 
também como uma forma de treinar estudantes no planejamento e execução de projetos.

Por meio da aprovação de novos projetos de empreendedorismo e de extensão pela Fundação de Amparo à Pesquisa da Bahia (FAPESB) e pelo Ministério da Educação (MEC), espera-se continuar as atividades. A FAPESB financia atualmente um projeto em execução que levará às famílias produtoras tecnologias de baixo custo, pela capacitação participativa, com ênfase no fomento ao desenvolvimento de ações empreendedoras por jovens rurais no município de Caraíbas. Haverá também o treinamento dos membros da Empresa Jr de Agronomia da UESB, que possibilitará a futura replicação em outros municípios.

O MEC possibilitará a execução de um programa para a indução do desenvolvimento rural sustentável, por meio da oferta de assistência técnica e apoio na produção e comercialização de alimentos da agricultura familiar nos 24 municípios do TVC, tornando os produtores aptos a acessarem o Programa Nacional de Alimentação Escolar (PNAE). O PNAE, que garante, por meio da transferência de recursos financeiros, a alimentação escolar dos alunos de toda a educação básica, matriculados em escolas públicas e filantrópicas, preconiza que $30 \%$ dos alimentos sejam adquiridos da agricultura familiar (FNDE, 2011).

O programa será desenvolvido com a participação de estudantes de Agronomia em parceria com a Base de Serviços e Colegiado do TVC. Assim, acredita-se que o processo de organização das comunidades do Território será fortalecido de forma a garantir a progressão do trabalho que vem sendo realizado, além de ampliar a área assistida com a inclusão de todos os municípios. Isso contribui para a formação de uma rede de cooperação, que deverá ser referência de qualidade e balizará outros projetos de interesse local/regional, que tenham como objetivos a melhoria da qualidade de vida e a inclusão social desse importante segmento da sociedade brasileira.

Todas as ações apresentadas não seriam possíveis sem a participação dos movimentos sociais, organizações, instituições, 
cooperativas, professores e estudantes, que contribuíram expressivamente na construção desse importante momento da agricultura familiar do TVC, a saber: Cooperativa Mista de Pequenos Agricultores do Sudoeste da Bahia (COOPASUB), Articulação do Semiárido (ASA), Centro de Convivência e Desenvolvimento Agroecológico do Sudoeste da Bahia (CEDASB), Colegiado do Território de Vitória da Conquista, Comissão Pastoral da Terra (CPT), Companhia de Desenvolvimento e Ação Regional (CAR), Companhia Nacional de Abastecimento (CONAB), Cooperativa de Pequenos Agricultores de Café de Barra do Choça (COOPERBAC), Cooperativa de Trabalho da Região Sudoeste da Bahia (COOPERSUBA), Cooperativa dos Produtores dos Derivados de Cana-de-açúcar da Região do Rio Gavião (COODECANA), Cooperativa dos Produtores dos Derivados de Leite da Região do Rio Gavião (COODELEITE), Cooperativa dos Produtores dos Derivados de Mandioca da Região do Rio Gavião (COOPERMAN), Cooperativa dos Produtores de Mel da Região do Rio Gavião (COOPMEL), Empresa Baiana de Desenvolvimento Agrícola (EBDA), Grupo de Economia Popular e Solidária (GEP), Instituto Mata de Cipó (IMC), Instituto Nacional de Colonização e Reforma Agrária (INCRA), Ministério da Agricultura, Pecuária e Abastecimento (MAPA), Ministério do Desenvolvimento Agrário (MDA), Ministério do Desenvolvimento Social (MDS), Movimento dos Pequenos Agricultores (MPA), Movimento de Trabalhadores Desempregados (MTD), Movimento dos Trabalhadores Sem-Terra (MST), Pólo Sindical, Prefeitura Municipal de Vitória da Conquista (PMVC), Secretaria de Agricultura do Estado da Bahia (SEAGRI), Serviço de Apoio às Micro e Pequenas Empresas da Bahia (SEBRAE), Sindicato de Trabalhadores Rurais da Região de Vitória da Conquista (STR-VC), Universidade Estadual do Sudoeste da Bahia (UESB). 


\section{Referências}

ABREU, R. W. M. de; BRITO, I. P. F. S. de; CONCEIÇÃO JUNIOR, V. Importância da diversidade produtiva para a agricultura familiar no município de Vitória da Conquista - Bahia. In: CONPEX, 11., 2008. Itapetinga, BA. Anais... Itapetinga, BA: UESB, 2008.

ALTIERI, M. A.; NICHOLS, C. Agroecologia: teoria y aplicaciones para una agricultura sustentable. Alameda: University California, 1999.

ARAÚJO JÚNIOR, V. G. de. Uma visão de diagnóstico do sistema agrário brasileiro. Revista CESUC, ano 5, n. 8, 2003.

BRASIL. Projeto de Cooperação Técnica INCRA/FAO. Novo retrato da agricultura familiar: o Brasil redescoberto. Brasília, 2000.

BRASIL. Diário Oficial da União, Brasília-DF, edição 190, seção 1, p. 84-85. $1^{\circ}$ out. 2008.

BRASIL. Ministério do Desenvolvimento Social e Combate à Fome (MDS). Guia de Políticas Sociais Quilombolas. Brasília, DF: MDS, 2009.

BRASIL, D. F. Técnicas de extensão com comunidades rurais. Natal: Departamento de Oceanografia e Limnologia da Universidade Federal do Rio Grande do Norte, 2011.

BRITO, I. P. F. S. de; VIEIRA, J. A., DEUS, S. J. S., SARMENTO, C. S. A. G., ALEIXO, D. A. V., NUNES, R. R., GALVAO, C. G., HEINE, A. J. M., SOUZA, F. N., CONCEIÇÃO JÚNIOR, V. Agricultura Agroecológica em Comunidades Quilombolas no Território da Região de Vitória da Conquista - Bahia In: CONGRESSO BRASILEIRO DE AGROECOLOGIA, 6.; CONGRESSO LATINOAMERICANO DE AGROECOLOGIA, 2., 2009, Curitiba. Anais... Curitiba, 2009.

CARNEIRO, M. J. Política Pública e Agricultura Familiar: uma leitura do Pronaf. Projeto Rurbano, 1999. Disponível em: <www.eco.unicamp. br/projetos/rurban14.html>.

CAVACO, C. Turismo rural e desenvolvimento local. In: RODRIGUES, Adir B. (Org.). Turismo e geografia: reflexões teóricas e enfoques regionais. São Paulo: Hucitec, 1996. 
CONCEIÇÃO JÚNIOR, V.; BRITO, I. P. F. S. de; ABREU, R. W. M. de; MENEZES, A. M. S.; PEREIRA, M. P. Sustentabilidade econômica dos sistemas de produção da agricultura familiar no município de Vitória da Conquista - Bahia. Revista Economia e Sociedade, Vitória da Conquista: ADTR/PMVC, v. 1, p. 21-30, 2008.

CONCEIÇÃO JÚNIOR, V.; SANTOS, V. C. C. A política territorial no Brasil de hoje: o exemplo do território da região de Vitória da Conquista - Bahia (TRVC). In: CONPEX, 11., 2008. Itapetinga, BA. Anais... Itapetinga, BA: UESB, 2008.

CREMONESE, C.; SCHALLENBERGER, E. Cooperativismo e agricultura familiar na formação do espaço agrícola do Oeste do Paraná. Revista Tempo da Ciência, Toledo, v. 12, n. 23, 2005.

DEUS, S. J. S.; BRITO, I. P. F. S. de; VIEIRA, J. A.; ALEIXO, D. A. V.; OLIVEIRA, U. S.; NUNES, R. R.; SANTOS, A. A.; CONCEICAO JUNIOR, V. A importância da aposentadoria na zona rural no município de Vitória da Conquista - Bahia. In: SEMANA DE AGRONOMIA DA UESB - SEAGRUS, 5., 2010, Vitória da Conquista. Anais... Vitória da Conquista, 2010.

EPE/TRVC. Estudo das potencialidades econômicas do território da região de Vitória da Conquista. Vitória da Conquista, 2007. 123 p.

FARIAS, D. H.; MENEZES, A. M. S.; BRITO, I. P. F. S. de; PEREIRA, M. P.; ABREU, R. W. M. de; CONCEIÇÃO JÚNIOR, V. Sustentabilidade econômica dos sistemas de produção praticados em Vitória da Conquista - BA. In: REUNIÃO ANUAL DA SOCIEDADE BRASILEIRA PARA O PROGRESSO DA CIÊNCIA (SBPC), 59., 2007, Belém. Anais... Belém, 2007.

FUNDO NACIONAL DE DESENVOLVIMENTO DA EDUCAÇÃO (FNDE). Alimentação escolar. Disponível em: <http:// www.fnde.gov.br/index.php/programas-alimentacao-escolar>. Acesso em: 05 abr. 2011.

GARCIA FILHO, D. P. Análise e diagnóstico de sistemas agrários - guia metodológico. Brasília, DF: INCRA/FAO, 1999.

GASSON, R.; ERRINGTON, A. The farm family business. Wallingford: Cab International, 1993. 
MENEZES, A. M. S.; FARIAS, D. H.; BRITO, I. P. F. S. de; PEREIRA, M. P.; ABREU, R. W. M. de; CONCEIÇÃO JÚNIOR, V. Estudo de viabilidade dos sistemas de produção da agricultura familiar na região rural-urbana do município de Vitória da Conquista - Bahia. In: CONPEX, 10., 2007, Vitória da Conquista. Anais... Vitória da Conquista, 2007.

OTANI, M. N; SOUZA, M. C. M.; VEIGA, J. E. R.; BORTOLETO, E. E.; VEIGA FILHO, A. A.; SILVA, J. C. R.; MELLO, R. L. Enfoque metodológico para o desenvolvimento sustentável de produtores familiares de Lagoinha, estado de São Paulo, Brasil. In: CONGRESSO BRASILEIRO DE ECONOMIA E SOCIOLOGIA RURAL, 24., 2000, Rio de Janeiro. Anais... Rio de Janeiro: SOBER, 2000.

PEREIRA, M. P.; MENEZES, A. M. S.; FARIAS, D. da H.; BONFIM, J. A.; ABREU, R. W. M.; CONCEIÇÃO JUNIOR, V. Perfil da agricultura realizada no entorno da sede do município de Vitória da Conquista BA. In: REUNIÃO ANUAL DA SOCIEDADE BRASILEIRA PARA O PROGRESSO DA CIÊNCIA - SBPC, 58., 2006, Florianópolis. Anais... Florianópolis, 2006.

PREFEITURA MUNICIPAL DE VITÓRIA DA CONQUISTA (PMVC). Curso de Formação de Lideranças Quilombolas. Vitória da Conquista, 2009.

SANTOS, A. A.; LACERDA, L. R. L.; BRITO, I. P. F. S. de; CONCEICAO JUNIOR, V. Manejo e Conservação dos Recursos Naturais em Comunidades Quilombolas na Micro-Região de Vitória da Conquista. In: SEMINÁRIO DE ENGENHARIA FLORESTAL DO SUDOESTE DA BAHIA: "RECURSOS FLORESTAIS PARA O SEMI-ÁRIDO”, 1., 2009. Vitória da Conquista. Anais... Vitória da Conquista, 2009.

VIEIRA, J. A.; ALEIXO, D. A. V.; BRITO, I. P. F. S. de; DEUS, S. J. S.; OLIVEIRA, U. S.; NUNES, R. R.; SANTOS, A. A.; CONCEICAO JUNIOR, V. Impactos do Programa Bolsa Família em Comunidades Rurais do Município de Vitória da Conquista - Bahia. In: SEMANA DE AGRONOMIA DA UESB - SEAGRUS, 5., 2010, Vitória da Conquista. Anais... Vitória da Conquista, 2010. 